\title{
A delayed diagnosis: stridor secondary to hypocalcemia
}

\author{
Fatih Büyükcam • Feruza Turan Sönmez• \\ Hayriye Şahinli
}

Received: 19 June 2010 / Accepted: 9 August 2010 /Published online: 23 October 2010

(C) The Author(s) 2010. This article is published with open access at Springerlink.com

\begin{abstract}
Hypocalcemia with stridor is a well-known condition in the pediatric age group but has rarely been reported in the elderly. We report an elderly patient who presented with dyspnea and laryngeal stridor attack caused by hypocalcemia. The patient had been suffering from stridor and dyspnea episodes for 2 years, and the etiology had not been determined until the evaluation in our department. The cause of stridor was hypocalcemia secondary to thyroidectomy. Complete resolution of stridor was achieved by calcium replacement therapy.
\end{abstract}

Keywords Hypocalcemia · Laryngospasm · Stridor ·

Postoperative complications

\section{Introduction}

The most common causes of stridor in adults are abscesses or swelling of the upper airway, tumors and paralysis or malfunction of the vocal cords. Laryngospasm due to hypocalcemia is a rare cause of stridor [1]. We report an elderly patient who presented with dyspnea and laryngeal stridor attack because of hypocalcemia. The patient had been suffering from stridor and dyspnea episodes for 2 years, and

F. Büyükcam $(\bowtie) \cdot$ F. T. Sönmez

Department of Emergency Medicine,

Diskapi Yildirim Beyazit Training and Education Hospital,

Ankara, Turkey

e-mail: fatihbuyukcam@gmail.com

F. Büyükcam

Yunus Emre Mahallesi, Nurlu Sokak 4/6, Yenimahalle,

Ankara, Turkey

H. Şahinli

Department of Internal Medicine,

Diskapi Yildirim Beyazit Training and Education Hospital,

Ankara, Turkey the etiology had not been found until her evaluation at our department. The cause of stridor was hypocalcemia secondary to thyroidectomy. Complete resolution of stridor was achieved by calcium replacement therapy.

\section{Case report}

A 54-year-old woman complaining of dyspnea and stridor was admitted to our hospital. She had a history of intermittent stridor and dyspnea for 2 years. In her medical history, it was learned that she had undergone a thyroidectomy operation 2 years ago. After that operation, she had not gone to the control examinations, and she had not used any medical treatment. But she had visited the pulmonologist because of stridor and dyspnea several times. In her previous examinations, fiberoptic bronchoscopy, thorax computed tomography and respiratory function tests were applied, and these tests were evaluated as normal by the pulmonologist, but her PTH level, thyroid function tests and calcium level had not been checked yet.

On examination in our emergency department, she was tachypneic, and her accessory muscles were joining in respiration. She had inspiratory stridor, and the inspiration duration was lengthened. On auscultation of her chest, normal vesicular breath sounds were heard; there was no wheezing or rhonchus. Arterial blood gases demonstrated respiratory alkalosis $\left(\mathrm{pH}: 7.46, \mathrm{pCO}_{2}: 33.2, \mathrm{pO}_{2}: 120.9\right.$, $\mathrm{HCO}_{3}: 23.7, \mathrm{sO}_{2}: 98.7$, iCa: $\left.0.272 \mathrm{mmol} / \mathrm{l}\right)$. The blood calcium level was $3.3 \mathrm{mg} / \mathrm{dl}$; other blood tests including thyroid function tests were normal: parathormone (PTH): $2.56 \mathrm{pg} / \mathrm{ml}(15-65 \mathrm{pg} / \mathrm{ml}), 25-\mathrm{OH}$ vitamin D3: $9.91 \mathrm{ng} / \mathrm{ml}$ (11.1-42.9 ng/ml). A 20-ml calcium gluconate $10 \%$ solution (180 mg elemental calcium) was given to the patient in $4 \mathrm{~h}$. After this replacement therapy, the severity of her stridor decreased. The calcium level at that moment was $4.9 \mathrm{mg} / \mathrm{dl}$, iCa: $0.879 \mathrm{mmol} / \mathrm{l}$. An additional $40 \mathrm{ml}$ of 
calcium gluconate was given for $16 \mathrm{~h}$. Her calcium level returned to baseline $(7.6 \mathrm{mg} / \mathrm{dl})$ after $20 \mathrm{~h}$ of calcium replacement therapy, and complete resolution of the stridor was achieved. Pulmonary auscultation was normal, and the patient was discharged from the emergency department for further evaluation at the endocrinology outpatient department. Oral calcium repletion was initiated by the endocrinologist. The patient was evaluated after 2 months, and during this period there were no stridor attacks. Also her calcium level was within normal range.

\section{Discussion}

The main postoperative complications of thyroidectomy include injury to the parathyroid glands and to the laryngeal nerves [2]. Injury to the parathyroid glands was manifested by temporary or permanent hypocalcemia. Transient hypocalcemia is commonly seen after thyroid surgery, as biochemical disorders are described in more than $83 \%$ of the cases. Clinical hypocalcemia is however less frequently observed [3]. Hypocalcemia leads to increased neuromuscular irritability and may present with circumoral numbness, paresthesias of the hands and feet, and muscular cramps, or when severe, with laryngospasm, focal or generalized tonic muscle cramps, or seizures. Myocardial dysfunction and prolongation of the QT interval may also occur [1].

In the literature, post-thyroidectomy hypoparathyroidism has been reported with a varying incidence, ranging from less than $1 \%$ to as high as $15 \%$ [4]. The extension of the thyroid resection procedure is a risk factor for the onset of clinical and laboratory hypoparathyroidism, while age above 50 years is a risk factor for clinical hypoparathyroidism [3]. Patients must be carefully observed in the postoperative period and have their laboratory workup done, especially those categorized as high risk patients [5]. In the reported case we explained that the patient had not gone to her control examinations, and her parathyroid hormone level had never been evaluated. Consequently, hypocalcemia had not been recognized for 2 years.

Severe hypocalcemia and hypomagnesemia resulting from malabsorbtion syndrome secondary to celiac disease in an elderly woman leading to laryngospasm has been reported [6]. Hypomagnesemia also results in increased neuromuscular irritability and perioperative laryngospasm from hypomagnesemia, and secondary hypocalcemia in a diabetic patient has also been reported [7].

In conclusion, it is suggested that in case of recurrent laryngospasm, electrolyte measurements of magnesium and calcium might be helpful in the diagnosis and treatment of the patients. Hypocalcemia should be considered in the differential diagnosis of stridor for elderly patients. Additionally, the patients must be followed for complications such as hypocalcemia after thyroidectomy.

Conflicts of interest None.

Open Access This article is distributed under the terms of the Creative Commons Attribution Noncommercial License which permits any noncommercial use, distribution, and reproduction in any medium, provided the original author(s) and source are credited.

\section{References}

1. Srivastava A, Ravindran V (2008) Stridor secondary to hypocalcemia in the elderly: An unusual presentation. Eur J Intern Med 19 (3):219-220. doi:10.1016/j.ejim.2007.04.020

2. Sakorafas GH, Stafyla V, Bramis C, Kotsifopoulos N, Kolettis T, Kassaras G (2005) Incidental parathyroidectomy during thyroid surgery: An underappreciated complication of thyroidectomy. World J Surg 29(12):1539-1543. doi:10.1007/s00268-005-0032-y

3. Dedivitis RA, Pfuetzenreiter EG Jr, Nardi CE, Barbara EC (2010) Prospective study of clinical and laboratorial hypocalcemia after thyroid surgery. Braz J Otorhinolaryngol 76(1):71-77. doi:S180886942010000100012

4. McHenry CR, Speroff T, Wentworth D, Murphy T (1994) Risk factors for postthyroidectomy hypocalcemia. Surgery 4(116):641647, discussion 647-648

5. Chia SH, Weisman RA, Tieu D, Kelly C, Dillmann WH, Orloff LA (2006) Prospective study of perioperative factors predicting hypocalcemia after thyroid and parathyroid surgery. Arch Otolaryngol Head Neck Surg 132(1):41-45. doi:10.1001/archotol. 132.1 .41

6. Waeber G, Pralong G, Breitenstein E, Nicod P (1993) Laryngospasm: unusual manifestation of celiac disease. Schweiz Med Wochenschr 123(10):432-434

7. Papaioannou A, Papantonaki S, Nyktari V, Psomopoulos H, Karatsis P, Fraidakis O, Askitopoulou H (2006) Hypomagnesaemia associated with diabetes mellitus may cause laryngospasm. Acta Anaesthesiol Scand 50(4):512-513. doi:10.1111/j.1399-6576. 2006.00985.x 